\title{
Estudo conceptual sobre produto de solubilidade e solubilidade
}

\author{
M. FERNANDA P. SILVA ${ }^{1, *}, M$. ROSÁRIO M. S. AFONSO${ }^{1}$ E SUSANA C. ROCHA
}

Procurou averiguar-se se professores profissionalizados com vários anos de experiência e professores em profissionalização (estágio integrado no $5 .^{\circ}$ ano da licenciatura em Ensino de Física e Química), apresentam conhecimentos claros e bem estruturados acerca da constante do produto de solubilidade e de solubilidade, e em que medida alunos do $12 .^{\circ}$ ano e alunos do $1 .^{\circ}$ ano da universidade retiveram esses conceitos. Aplicou-se um inquérito aos alunos e outro aos professores, com questões de escolha múltipla, contendo duas questões comuns: uma sobre a formulação do Princípio de Le Chatelier e a outra sobre a definição do produto de solubilidade. O questionário dos professores tinha ainda uma questão sobre solubilidade molar. Verificou-se que o enunciado do Princípio de Le Chatelier, estava bem presente em todos os inquiridos; já não aconteceu o mesmo com a outra questão, onde os professores com experiência apresentaram um melhor desempenho que os professores em formação, e os alunos do $12 .^{\circ}$ ano também apresentaram melhor resultados que os dos alunos do $1 .^{\circ}$ ano da universidade.

\section{Introdução}

Os conceitos de produto de solubilidade e de solubilidade estão intimamente relacionados com outros conceitos químicos, como equilíbrio químico, equilíbrio de solubilidade e Princípio de Le Chatelier (também conhecido por Princípio de Le Chatelier e Braun [1-2]).

O conceito de equilíbrio químico é um conceito abstracto e é considerado como um dos conceitos mais difíceis do processo ensino-aprendizagem em Química [3]. As dificuldades são sentidas quer por professores quer por alunos. Aqueles, porque nem sempre têm uma concepção absolutamente clara do conceito que pretendem ensinar e estes porque, durante a aprendizagem daquele conceito, adquirem várias concepções erradas [4-5]. Há alguns aspectos específicos que contribuem para concepções erradas de equilíbrio químico, como por exemplo: a própria

\footnotetext{
${ }^{1}$ Universidade de Aveiro - Departamento de Química - 3810-193 Aveiro.

*E-mail: mfs@dq.ua.pt
}

essência do conceito de equilíbrio químico [6-9], deslocamento para a direita e para a esquerda [9-11], efeito da adição de um catalisador [12], alterações das condições de equilíbrio $[6,9,13]$, aplicação do Princípio de Le Chatelier a equilíbrios homogéneos em fase gasosa [14], uso de certos algoritmos na resolução de problemas de equilíbrio [15], confusão entre velocidade e extensão de reacção [13], modelos usados pelos professores para a construção mental do conceito de equilíbrio químico [16], analogias utilizadas quer por professores, quer em livros de texto [9,17], analogias que os próprios alunos fazem com a linguagem usada em Física e no dia-a-dia [6,12], as próprias concepções que os professores têm [5], as excepções à aplicação do principio de Le Chatelier [1,18], etc. O equilíbrio de solubilidade, como um caso peculiar do equilíbrio químico, apresenta, além das já citadas dificuldades, outras por parte dos alunos, de compreensão a nível do conceito de solubilidade e da própria constante do produto de solubilidade; como, por exemplo, quando se pede a aplicação do Princípio de Le Chatelier a um sistema heterogéneo em que se altera a massa de sólido adicionada ao sistema [11] (embora alguns alunos saibam resolver correctamente problemas envolvendo solubilidade e a constante do produto de solubilidade, nem sempre compreendem o conceito em si [19]).

Os estudos referentes ao presente trabaIho envolveram professores e alunos dos dois últimos anos do ensino secundário e do $1 .{ }^{\circ}$ ano da universidade (nos conteúdos programáticos dos alunos do ensino secundário o tópico equilíbrio químico (e princípio de Le Chatelier) é leccionado no $11 .^{\circ}$ ano de escolaridade). Este estudo pretendeu averiguar se os alunos compreenderam os conceitos de solubilidade e constante do produto de solubilidade e se os professores têm esses conceitos bem claros e estruturados, de modo a poderem usarem linguagem científica adequada (absolutamente essencial para o ensino em ciência [20]), e fazer a comparação entre os resultados dos grupos de inquiridos. 
Tabela 1 Enunciado da Questão Q1 e respostas em \% por grupo de inquiridos (I: alunos $12 .^{\circ}$ ano; II: alunos $1 .^{\circ}$ ano UA; III: professores)

\begin{tabular}{lccc}
$\begin{array}{l}\text { O Princípio de Le Chatelier afirma que sempre que um equilíbrio é } \\
\text { perturbado... }\end{array}$ & I II & III \\
\hline $\begin{array}{l}\text { A }-\ldots \text { a reacção tende a progredir no sentido directo para diminuir } \\
\text { esse efeito, até se atingir novo estado de equilíbrio }\end{array}$ & 0 & 7 & 0 \\
\hline $\begin{array}{l}\text { B }-\ldots \text { a reacção tende a progredir no sentido de aumentar essa per- } \\
\text { turbação }\end{array}$ & 0 & 0 & 0 \\
\hline C $-\ldots$ a reacção tende a libertar energia térmica & 0 & 0 & 0 \\
\hline $\begin{array}{l}\text { D }-\ldots \text { a reacção tende a progredir no sentido de contrariar essa per- } \\
\text { turbação, até se atingir novo estado de equilíbrio }\end{array}$ & 100 & 93 & 100 \\
\hline
\end{tabular}

\section{Parte experimental}

\section{Questionário e amostras usadas}

A metodologia de trabalho consistiu na aplicação de dois questionários: um a professores e o outro a estudantes. Os questionários eram formados por cinco questões de escolha múltipla; cada questão apresentava 4-5 opções, e pedia-se que fosse $(\mathrm{m})$ assinalada(s) a(s) questão(ões) correcta(s). Os dois questionários tinham duas questões comuns: uma destas questões era sobre a identificação do enunciado do Princípio de Le Chatelier, e a outra sobre a definição científica de constante do produto de solubilidade. As outras três questões do inquérito aplicado aos alunos eram sobre aplicação do Princípio de Le Chatelier a sistemas em equilíbrio: num, em fase aquosa, a variável era a concentração de um dos reagentes; noutro, a questão envolvia a variável temperatura e no outro, em fase gasosa, havia alteração da pressão do sistema (equilíbrio de síntese do $\mathrm{HCl}$ em fase gasosa). No inquérito aplicado aos professores eram duas as questões referentes à aplicação do Princípio de Le Chatelier que apresentavam maior grau de dificuldade que as dos alunos: uma envolvia a variável temperatura e a outra a libertação de um gás em sistema aberto. 0 inquérito dos professores continha ainda uma questão sobre a definição de solubilidade molar.

Nas questões postas nos dois inquéritos, escreveu-se na expressão da constante de equilíbrio, dos equilíbrios químicos referidos no trabalho, as concentrações das espécies iónicas envolvidas e não as respectivas actividades; isto deveu-se ao facto de o estudo se referir a solubilidade de sais pouco solúveis; neste caso o coeficiente de actividade de cada um dos iões presentes em solução é praticamente igual a um $\left(\gamma_{i}=1\right)$, pelo que o facto de se considerar a concentração molar, $c_{\mathrm{i}}$, de cada uma das espécies iónicas, em vez da sua actividade, $a_{i}$, não vai influenciar os resultados $\left(a_{i}=\right.$ $\left.\gamma_{i} c_{\mathrm{i}}\right)$. A população alvo era constituida por três grupos distintos: um formado por professores em profissionalização, do núcleo de estágio integrado no último ano da licenciatura em Ensino de Física e Química da Universidade de Aveiro, U.A., em número de dez, e professores com experiência de docência a leccionar numa escola do distrito de Aveiro, em número de doze ( $N=22)$; um segundo grupo formado por alunos do 12 . $^{\circ}$ ano, em número de dezanove $(\mathrm{N}=19)$; e o último grupo formado por alunos do $1 .{ }^{\circ}$ ano da U.A. a frequentarem a disciplina de Química I, em número de quarenta e seis $(N=46)$. As respostas ao questionário foram dadas no momento, após a sua leitura, sem recurso a qualquer tipo de consulta; os alunos da universidade responderam no final de uma aula laboratorial de duas horas, em que realizaram um trabalho moroso.

\section{Resultados e sua análise}

Os resultados obtidos para cada uma das duas questões comuns aos dois questionários, a seguir designadas por Q1 e Q2 irão ser apresentados em paralelo para os três grupos de inquiridos,

Tabela 2 Enunciado da Questão Q2 e respostas em \% por grupo de inquiridos (I: alunos 12. ${ }^{\circ}$ ano; II: alunos 1. ${ }^{\circ}$ ano UA; III: professores)

Pode afirmar-se que constante do Produto de Solubilidade,

\begin{tabular}{lccc}
$\boldsymbol{K}_{\mathbf{S}}$, é... & I & II & III \\
\hline $\begin{array}{l}\text { A }-\ldots \text { o valor da constante de dissociação de um qualquer } \\
\text { sólido }\end{array}$ & 21 & 15 & 14 \\
\hline $\begin{array}{l}\text { B }-\ldots \text { o produto das concentrações dos iões em equilíbrio } \\
\text { a dividir pela concentração de sólido presente em solução } \\
\text { aquosa }\end{array}$ & 11 & 27 & 23 \\
\hline $\begin{array}{l}\text { C }-\ldots \text { a concentração de sólido em solução aquosa a dividir } \\
\text { pelo produto das concentrações dos iões em equilíbrio }\end{array}$ & 0 & 26 & 0 \\
\hline $\begin{array}{l}\text { D -... o produto das concentrações dos iões em equilíbrio } \\
\text { com o sólido em solução aquosa }\end{array}$ & 68 & 30 & 41 \\
\hline
\end{tabular}


nas tabelas 1 , e 2 , respectivamente. Os resultados da questão, Q3, sobre a definição científica de solubilidade molar, apenas posta aos professores, serão apresentados na tabela 3. Para cada uma das questões as opções escolhidas pelos inquiridos são referidas em percentagem.

Como se pode observar da tabela 1 os professores e os alunos do $12 .^{\circ}$ ano têm bem presente o enunciado correcto do Princípio de Le Chatelier; contudo 7\% dos alunos do $1 .^{\circ}$ ano da universidade

Tabela 3 Enunciado da Questão Q3 e respostas, em \%, dadas pelos professores

\begin{tabular}{lc} 
Solubilidade molar (de um sal pouco solúvel) ... & Resposta / \% \\
\hline $\begin{array}{l}\text { A }-\ldots \text { é a concentração molar (do sólido que não se dissolve) numa solução } \\
\text { saturada }\end{array}$ & 0 \\
\hline B $-\ldots$ é a concentração molar (do sólido que se dissolve) numa solução & 18 \\
\hline $\begin{array}{l}\text { C }-\ldots \text { é a concentração molar (do sólido que se dissolve) numa solução } \\
\text { saturada }\end{array}$ & 64 \\
\hline D $-\ldots$ é a quantidade de sal que se dissolve num certo volume de líquido & 18 \\
\hline E - Nenhuma das anteriores & 0 \\
\hline
\end{tabular}

Tabela 4 Comparação das respostas correctas dadas pelos inquiridos às duas questões comuns, Q1 e Q2, e à questão Q3 sobre definição de solubilidade molar colocada aos professores

$\%$ Respostas correctas

\begin{tabular}{ccccc}
\hline & \multicolumn{2}{c}{ Professores } & \multicolumn{2}{c}{ Alunos } \\
\hline Questões & Experientes & Estagiários & $12 .^{\circ}$ ano & $1 .^{\circ}$ ano U.A. \\
\hline Q1 & 100 & 100 & 100 & 93 \\
\hline Q2 & 67 & 10 & 68 & 30 \\
\hline Q3 & 67 & 50 & 42 & 35 \\
\hline
\end{tabular}

associam a alteração do equilíbrio apenas a um deslocamento no sentido directo.

Para a questão 2, além das opções apresentadas na tabela 2 , houve outros tipos de categorias de resposta (não respondeu e resposta simultânea de A e B) que serão discutidas na análise que se faz a seguir à tabela.

Da análise da tabela 2 observa-se uma grande diversidade de respostas, especialmente nos alunos do $1 .^{\circ}$ ano da U.A.; destes, $15 \%$ demonstram que associam

a solubilidade de um sal iónico à sua dissociação, assim como também alguns alunos do $12 .^{\circ}$ ano, mas não têm presente se o sal é muito ou pouco solúvel (opção $A$ ), o que denuncia alguma dificuldade de interpretação da linguagem científica; contudo são os alunos do $12 .^{\circ}$ ano os que têm mais presente o significado correcto da questão. De entre os alunos do $1 .^{\circ}$ ano houve $2 \%$ que responderam simultâneamente às opções A e B. Nos professores nota-se alguma confusão nas opções que fize-

$\sqrt{2+2}$


A última questão colocada aos alunos pedia o efeito da variação da temperatura em equilíbrios referentes a reacções endo e exotérmicas. Dos alunos do $12 .^{\circ}$ ano, 95\% responderam bem e dos do $1 .^{\circ}$ ano da U.A. a percentagem de respostas correctas (54\%) foi inferior novamente, à dos alunos do $12 .^{\circ}$ ano, e inferior à resposta que eles deram à questão Q4.

As respostas à questão posta aos professores (sobre o efeito da temperatura) mostraram que a maioria (86\%) tem bem presente o efeito da temperatura num processo, mas seria de esperar uma percentagem total de respostas correctas; 9\% deles deram precisamante a resposta oposta.

\section{Conclusões}

Das respostas dadas às questões analisadas pode concluir-se que, quer os professores quer os alunos, têm bem presente o enunciado do Princípio de Le Chatelier e Braun. Na questão relativa à definição de produto de solubilidade (Q2) as respostas dos alunos do 1. ${ }^{\circ}$ ano da universidade foram baixas (estes alunos preencheram o inquérito após uma aula laboratorial de química de duas horas); os alunos do $12 .^{\circ}$ ano responderam bastante melhor, facto que se pode interpretar por terem os conhecimentos ainda muito recentes. As respostas dos professores não foram muito positivas, facto que pode significar falta de conhecimentos. Quanto à definição de solubilidade molar, apenas colocada aos professores, verificou-se uma maioria de respostas correctas, mas esperava-se uma percentagem mais significativa (não o foi especialmente pelas respostas dos estagiários); isso leva-nos a concluir que, ou não perceberam as diferenças que davam sentido às diferentes opções da questão ou não conhecem na realidade a definição cientificamente correcta.

Detectaram-se algumas concepções alternativas nos alunos, tais como:

1. Quando um equilíbrio é perturbado, o sistema evolui no sentido directo;

2. A variação da concentração de um reagente não afecta o sistema em equilíbrio;
3. Num sistema em equilíbrio em que $\Delta n_{\text {reacção }}=0$, um aumento da pressão perturba o equilíbrio;

4. A concentração do sal no estado sólido entra na expressão da constante do produto de solubilidade;

5. Um composto iónico com $K \mathrm{~s}=$ $8,7 \times 10^{-9}$ é completamente insolúvel.

Algumas sugestões que se propõem para melhorar o processo ensino-aprendizagem são:

1. usar linguagem cientificamente correcta;

2. utilizar analogias adequadas e em contexto correcto;

3. questionar os alunos sobre o facto de um sal ser pouco ou muito solúvel quando se fala em constante de produto de solubilidade;

4. comparar valores de constantes de produtos de solubilidade de vários sais, à mesma temperatura;

5. pedir aos alunos para compararem valores das solubilidades de sais, com igual estequiometria, conhecendo os valores das respectivas contantes de solubilidade;

6. desenvolver jogos adequados que estimulem a curiosidade do aluno [21];

7. usar simulações em computador [22]

Bibliografia:

Na bibliografia citada não se pretendeu ser exaustivo

[1] D. S. Corti , E. I. Franses, Chemical Engineering Education (2003) 290-295

[2] S. I. Sandler, Chemical and Engineering Thermodynamics, John Wiley \& Sons, Inc., N. Y., 1999

[3] F. N. Finley, J. Stewart, W. L. Yarroch, Science Education 66(1982) 531-538

[4] K. Tobin, M. Espinet, Journal of Research in Science Teaching 26 (1989) 105-120

[5] J. Quílez-Pardo, J. J. Solaz-Portolés, Journal of Research in Science Teaching 32 (1995) 939-957
[6] W. Bergquist, H. Heikkinen, Journal of Chemical Education 8 (1990) 10001003

[7] A. Huseyin, K. Hakki, B. Atasoy, O. Geban, Research in Science \& Technological Education 21(2003) 209-227

[8] M. Camacho, R. Good, Journal of Research in Science Teaching 26(1989) 251-272

[9] A. F.C. Cachapuz, R. Maskill, International Journal of Science Education 21 (1989) 235-246

[10] C. J. Furió, E. Ortiz, Enseñanza de las Ciencias 2 (1983) 15-20

[11] M. Gorodetsky, E. Gussarsky, European Journal of Science Education, 8 (1986) 427-441

[12] E. Gussarsky, M. Gorodetsky , Journal of Research in Science Teaching $\mathbf{2 7}$ (1990) 197-204

[13] A. C. Banerjee, International Journal of Science Education 13 (1991) 487-494

[14] B. Huddle, Journal of Chemical Education 75 (1998) 1175

[15] P. S. Matsumoto, Journal of Chemical Education 82 (2005) 406-407

[16] M.-H. Chiu, C.-C. Chou, C.-J. Liu, Journal of Research in Science Teaching 39 (2002) 688-712

[17] M. B. P. A. Pereira, Equilíbrio Químico - Dificuldades de Aprendizagem e Sugestões Didácticas, Sociedade Portuguesa de Química, Lisboa, 1990

[18] J. E. Lacy, Journal of Chemical Education 82 (2005) 1192-1193

[19] M. Nakhleh, Journal of Chemical Education 70 (1993) 52-55

[20] C. Sutton, Enseñanza de las Ciencias, 21 (2003) $21-25$

[21] M. F. P. Silva, M. R. M. S. Afonso, S. C. Rocha, "O Jogo do Equilíbrio", in Seminário da Licenciatura em Ensino de Física e Química, Universidade de Aveiro, Aveiro, 2004

[22] J. C. Paiva, V. M. S. Gil, A. F. Correia, Journal of Chemical Education 79 (2002) 640-641 